\title{
Whips, Chains and Books on Campus: How Organizations Legitimate Their Stigmatized Practices
}

\author{
Erica Coslor \\ Lecturer in Management \\ University of Melbourne \\ Brett Crawford \\ Assistant Professor \\ Purdue University \\ Barbara G. Brents \\ Professor of Sociology \\ University of Nevada, Las Vegas
}

\begin{abstract}
This paper explores how emergent organizations with core stigma and taboo practices work to gain widespread acceptance, extending work on organizational legitimacy and highlighting the growing number of purpose-driven organizations. We focus on emergent organizations because little is known about how they become established in the first place. We examine the intersection of core stigma and strategies in emergent, purpose-driven organizations through the provocative case of official university student organizations focused on kink and kinky sexuality. From examination of these organizations' historical emergence and university-sanctioned constitutions, we posit that (1) due process and impersonal evaluation processes enable recognition of taboo topics, particularly if official sanction is focused on organizational structure and roles and (2) organizations leverage credible social discourses, such as individual rights, to emphasize issues both pertinent to sanctioning organizations and mainstream throughout society. This research is timely given the explosion of emergent organizations today with socially taboo purposes.
\end{abstract}

\section{Keywords}

Core stigma, purposeful organizations, legitimacy, student organizations, constitution, university, neoliberalism, sexuality 


\section{Introduction}

One provocative way to learn about organizations is to examine negative cases. Cases of stigmatized and taboo domains provide fertile ground to see more clearly the processes and factors that can move organizations toward legitimacy, or conversely, factors that legitimate an organization despite its continued focus on a taboo area. In the first instance, we see many examples of organizations working in areas that were previously stigmatized or taboo, both in organizational research and the sociological literature. These include the development of life insurance (Zelizer, 1978), gay marriage (Creed, Scully \& Austin, 2002) and African American studies (Rojas, 2006). Tying into the extensive research on organizational legitimacy and social movements (Lee, 2009; Suchman, 1995), one way that organizations might mediate the reception and understanding of a taboo domain is by ritually conforming to expected norms to create a credible area for organizational work, particularly if this would enable recognition by an overarching sanctioning body. In contrast to these fully legitimated examples, other organizations face lasting challenges due to their core stigma — that fundamental stigma residing at the heart of an organization's purpose (Hudson, 2008). Such organizations may be associated with activities deemed illegal, such as prostitution (Kulik, Bainbridge \& Cregan, 2008), but many more examples include legal practices and concepts with a continuing taboo, requiring these organizations to deflect and mediate this core stigma. As seen with men’s bathhouses (Hudson \& Okhuysen, 2009), global arms companies (Vergne, 2012), medical marijuana (Hsu, Kovács \& Koçak, 2016) and Nevada’s legal brothels (Wolfe \& Blithe, 2015), established organizations with core stigma seem to draw upon a different repertoire of strategies in attempt to deflect their taboo reputations and mediate stigmatized associations. 
We know far less, however, about how emergent organizations with core stigma position themselves to gain legitimacy and acceptance, particularly when it comes to formal processes of recognition by an overarching body. The organizational core stigma literature notes efforts to reframe through discourses and sensemaking, divesting assets, diversifying holdings, lack of transparency, shifting to new categories and rationalizing certain practices (Creed, DeJordy \& Lok, 2010; Durand \& Vergne, 2015; Hudson \& Okhuysen, 2009; Reinmoeller \& Ansari, 2016; Vergne, 2012). A key channel for stigma deflection or organizational legitimation is the use of discourse (e.g. Rojas, 2010), which is likely to be a key tool if an organization faces an overarching sanctioning body, such as a regulator. While noting that these activities depend in part on the nature of the stigmatized activities, in focusing on different types of strategic efforts to mediate stigma and build recognition in emergent organizations, we wonder if it is possible to identify distinct organizational actions that are likely to receive recognition by a sanctioning body. This is important, because sometimes it is small changes that help to enable later, radical change (Plowman et al., 2007), with official recognition as a likely step towards eventual legitimacy.

One force motivating our study is the recent explosion in the number of organizations with a sense of rationality and conviction towards social issues (Bromley \& Meyer, 2015; Ebrahim, Battilana \& Mair, 2014). These emergent, “purpose-driven organizations” naturally include a subset with core stigma, where regardless of persistent strategic efforts, taboo associations remain, and are part of what motivate organizational incorporation. The emergence of these organizations also exemplifies a broader cultural shift, one where neoliberal rights and empowerment discourses motivates organizations with purpose (J. W. Meyer \& Bromley, 2013). At the same time, the lack of legitimacy means these organizations must also confront discourses 
that frame their actions as immoral, wrong or stigmatized. How they respond is an important question. For example, Hudson and Okhuysen (2009) illustrated how men’s bathhouses countered stigma by promoting sexual safety and positivity. We can also see echoes of these processes in areas that have been legitimated. For example, Creed and colleagues (2002) examined cultural frames used to construct a sense of legitimacy around LGBT workplace discrimination prevention. Existing research, however, tends to focus on change efforts in established organizations or contexts where stigmatized associations have been successfully legitimated. Far less is known about how emergent organizations with core stigma develop enough acceptance to become established in the first place. We posit that the intersection between emergent organizations and the phenomenon of core stigma also represents a poorly understood, yet important area of inquiry.

When it comes to purpose-driven emergent organizations and their search for recognition, the university campus provides an environment with elements of regulation, official sanction and wide representation of issues. With numerous student organizations existing in a typical university setting, ranging from television production to ethnic affiliations to sports to sexuality, official student organizations provide a microcosm of the work done by organizations to incorporate, form a purpose, and seek official recognition of their goals from an overarching body. Groups require student officers, roles and formal functions not only to pass muster with university sanction, but also to provide a level of organization to ensure the continuation of student organizations, echoing issues seen in various organizations. Yet official student organizations on university campuses span far beyond pre-professional development, instead emphasizing the neoliberal interests of twenty first century college students. Many are at the bleeding edge of social change, carrying the torch for a longer history of student activism (Rojas, 
2006). Moreover, the First Amendment generally prohibits colleges and universities from denying student organizations access to school-sponsored forums because of their viewpoints and more school-specific non-discrimination policies can prohibit who joins organizations (Heilpern, 2015). Thus student organizations devoted to topics deemed taboo in wider society provide an ideal context to study the concept of core stigma, while also sharpening our sensitivity to under-examined factors and processes through the use of an unconventional research context (Bamberger \& Pratt, 2010).

We chose student organizations focused on kink as emergent organizations with core stigma attempting to gain official sanction within universities, with examples at Harvard University, Stanford University and the University of Chicago. We chose kink because it clearly meets the criteria of being historically recognized as taboo. Kink is defined as any unconventional sensual, erotic and sexual behavior and can include domination, submission, pain, humiliation, sensory deprivation, and exhibitionist, voyeuristic or fetishistic behaviors (Nichols, 2006; Rehor, 2015). Kink represents consensual sexual activities that society largely views as bizarre and unconventional (Tomassilli, Golub, Bimbi \& Parsons, 2009; Weiss, 2006). Conveniently, student organizations are amenable to study via organizational documents, which can reveal key organizational discourses and justifications of legitimacy, where discourses help to stabilize and destabilize different practices (Llewellyn, 2004; Maguire \& Hardy, 2013). In this paper, we examine discourses used by emergent student organizations focused on kinky sexuality in their constitutions as they gain official sanction within the broader field of student organizations with pre-professional purposes. Using student club constitutions, we addressed the following research question: How do organizations centered around stigmatized practices (i.e. with "core stigma") become recognized and thus legitimate as valid and necessary organizations? 
More specifically, how do emergent student organizations focused on kink become legitimate student organizations in the same category as student organizations without taboo associations? While student organizations focused on kink have faced roadblocks in attempting to gain official university recognition, we include successful examples, allowing us to examine the strategies of legitimated organizations with core stigma.

We begin by detailing recent research on core stigma, focusing on organizational strategies to deflect stigmatized associations and create widespread acceptance. We continue by detailing the literature on organizational documents as an indicator of key discourses related to different practices and stakeholders, then introduce the research context of stigmatized student organizations, where LGBT groups provide a prior example of sexual stigma on campus. Using thematic analysis of student constitutions in U.S. universities, the findings explore the discourses used by student organizations focused on kink in the constitutions that allow official recognition by universities. Our discussion includes a pair of insights into (1) how procedures and processes assist emergent organizations with core stigma in their purposeful efforts to gain legitimacy, with official recognition as a first step, i.e. focusing on the role of due process as a channel for legitimation through bureaucratic conformity. (2) How organizations discursively emphasize credible social issues that are both pertinent and mainstream throughout society when seeking official sanction.

\section{Organizations Addressing Core Stigma}

Organizational stigma and taboos are understudied—but important—concepts that can help us to understand legitimacy processes in new ways. Historically, work on stigma finds that individuals and organizations perceived to be outsiders are stigmatized. Additionally, stigmatized associations can be contagious to other people and organizations, as was the case for employees 
blacklisted as communists, and their associates, during the Hollywood Red Scare (Pontikes, Negro \& Rao, 2010), while stigma disclosure can be problematic for individuals (Ragins, 2008). Stigma transfer can also pose problems for organizations wanting to work in an area or on a topic with stigmatized associations (Hudson \& Okhuysen, 2009). Existing stigma research in the organizations area tends to focus on organizational strategy, for example, how firms in the global arms industry divest assets to reduce associations with stigmatized and attacked industries (Durand \& Vergne, 2015). Similarly, Vergne (2012) showed how firms engaged in category straddling as a means to divert stakeholder attention away from a given stigmatized association toward a more legitimate area, particularly in times of media attack, while Hsu et al. (2016) note the divergence in the way that marijuana dispensaries discuss their products, depending on whether the location is more or less receptive. Yet existing research tends to be focused either on responses to stigma in established organizations or on broader social movements that may involve groups within firms. In order to examine how emergent organizations with purpose mediate core stigma, principles from two areas of existing research seem especially relevant: how organizations actively create shifts from stigmatized to legitimate and in cases where stigmas remain, how organizations deflect stigmatized associations.

First, a diverse set of research explores how organizations actively create shifts from stigmatized to legitimate through reframing discourses. This is especially evident in sociological studies. For example, in the history of life insurance or “death markets” (Quinn, 2008), we find firms needing to change the framings around the meanings of these products, e.g. reframing life insurance away from an immoral "gambling" with the life of the insured to the protection of widows and children who would otherwise be left destitute (Zelizer, 1983). A wide range of research on sexuality has demonstrated how birth control, condoms, BDSM practices and 
policies of sex workers became legitimated through a medical and disease-prevention framework - a health and safety exception to morality that reframes and normalizes formerly taboo practices and topics (cf. Brents \& Hausbeck, 2001, 2005; Gamson, 1990; Hawkes, 1996; Lindemann, 2010; Weiss, 2006). For example, the medicalization of erectile dysfunction as a medical issue needing treatment both reframes the topic away from embarrassing "failure," or real but equally difficult-to-face psychological issues, and towards a common physical situation that also builds a market for prescription drugs.

The success of these reframing efforts clearly depends on the issues of concern, in addition to organizational strategies. The wider social context also matters for issue reception. For example, recent research on contemporary culture has pointed out that late capitalism is accompanied by an ethic that elevates individual freedom to choose one's lifestyle as a guiding human value, affecting gender and sexual relations and attitudes (Bauman, 2003; Giddens, 1992; Harvey, 2007; Hawkes, 1996). For example, neoliberal values of free choice and tolerance have been used to justify core stigma around prostitution (Bernstein, 2001; Brents, 2016; Prasad, 1999). This allows organizations related to sex and sexuality to build on a framework of individual rights, free choice and existing categories that are recognized as deserving protection from discrimination (Lakkimsetti, 2014; Richardson, 2000). In other words, wider social discourses can enable particular organizational strategies.

An important question is how organizations deflect stigmatized associations when the stigma remains, i.e. “core” organizational stigma (Hudson, 2008). Discourses take an important role in these ongoing efforts. For example, Hudson and Okhuysen’s (2009) ethnography illustrated how men's bathhouses used discourse to position the organization as a vehicle for sexual safety and awareness, which is categorically divergent from traditional social attitudes on 
men's bathhouses. Equally so, Creed and Scully (2000) explored the discourse used by LGBT employees in disclosing their social identity in the workplace. This work was later extended by studying how discourse was used to build legitimacy and organizational culture emphasizing acceptance of LGBT workplace policies (Creed et al., 2002). Moreover, reframing and change efforts can take decades or more—as seen in women's rights—-thus potentially requiring similar strategies of mediating a current stigma, such as discursive strategies, in addition to supportive organizations and communities.

While management and organization theory research on student organizations is limited (M. D. E. Meyer, 2004), we might question whether we will find similar organizational strategies when it comes to stigmatized issues. Existing work suggests that freedoms of speech and association buttress the institution of higher education (Gibbs, 1978), representing key discourses that legitimate the presence and expansion of student organizations. Campus administrators may see the mere existence of student organizations as indicators of a diversity-friendly campus climate, regardless of whether it actually reflects an accepting culture (Kane, 2013). Meyer (2004, p. 508) described student organizations as empowering to students, functioning as a vehicle to interact with "others like me.” Student organizations show the energy of students organizing around key social issues. For example, few university campuses exist today without one or more student organization relating to LGBTQI. Prior to the acceptance of lesbian and gay groups on university campuses, sexual stigmas were largely viewed as invisible (Goffman, 1963). LGBTQI identities and sexuality were until recently viewed as taboo, positioned as a disease to be cured, with strong stigma-by-association implications, and few student organizations were sanctioned as officials feared the public response (Anteby \& Anderson, 2014; Reichard, 2010). Student groups fought back. Many won lawsuits charging that universities 
violated their free speech rights (Gibbs, 1978). A growing acceptance of coming out moved this prior stigma into a realm that was observable, with refusal to pass for what had been socially constructed as normal as something that could be flaunted (Yoshino, 2006). However, this type of organizational activism often requires a level of coordination, for which we focus on organizational documents.

\section{Research Design}

\section{Research Context}

We utilize a unique research context (Bamberger \& Pratt, 2010), one that takes an extreme case to show processes related to emergent organizations with core stigma. We chose official student organizations dedicated to kinky sexuality on campus to examine how they deal with their core stigma to attain official university sanction. Kink can be viewed as a practice and community, and we find burgeoning awareness and academic exploration of kink, BDSM, sadomasochism and risk (Lindemann, 2010; Newmahr, 2011; Weiss, 2011), suggesting a potential interest in this stigmatized area.

Kink can also be viewed as a sexual identity. In this formulation, kink fits within a much more general legitimation of sexual identities (Weeks, 2007: 78). Categories such as "gay,” "lesbian,” "bisexual” and "trans” help to shape everyday practices relating to those issues (Jones \& Ward, 2010). We anticipate that the emergence of student organizations relating to kink will have a similar impact on the legitimation of practices associated with kink.

\section{Formal Organizational Documents Used to Define Purpose and Process}

Organizational actorhood has become both legitimate (Bromley \& Meyer, 2015) and legal (Horwitz, 2014) in postindustrial society. To define the boundaries of their actorhood, organizations have used a variety of formal documents to detail organizational values, purpose 
and behavioral expectations. Such documents include codes of ethics, by-laws, handbooks and constitutions, which are increasingly being adopted on a global scale (Carasco \& Singh, 2003). Historically, such documents played a significant role in the corporate sector as a means to outline behavioral expectations and operational procedures—most commonly using Roberts Rules of Order—and formalizing such procedures for a variety of stakeholder groups including employees, managers and investors (Treviño, Butterfield \& McCabe, 1998). Subsequently, these documents have effectively shaped managerial actions, where actions normatively align with legal justification above and beyond the morality of individual managers, dovetailing with strategic concerns about organizational mission and vision (Collins \& Porras, 1996).

The use of formal documents has also expanded beyond corporate contexts to rapidly growing nonprofit organizations with a heightened sense of rationality and values (Baccaro \& Mele, 2011; Bromley \& Orchard, 2015). Similarly, student organizations on university campuses are expected to prepare documents that set out the purpose, goals and operational processes of the organization before they can become officially recognized by the university, most commonly through a constitution. Most universities standardize this process by detailing the specific parts of the constitution, through guidelines and boilerplates. Boilerplates are effective in helping students that generally lack the experience of authoring such documents. Standardization of constitutions aims for consistency across applications of prospective organizations and provides an opportunity for the university to officially sanction or reject the student organization though administrative processes. These boilerplates tell us something about the process of all established student organizations, including those with core stigma.

For example, Harvard University's Office of Student Life uses an application process that includes a constitution detailing the prospective organization’s name, purpose, membership, 
officers, elections and meetings (Harvard College, 2015). Vanderbilt University provides a constitution and by-law boilerplate with similar categories as Harvard, but requires additional details on parliamentary practice (Vanderbilt University, 2015). Finally, the University of Michigan states that, "The process of writing a constitution will serve to clarify your purpose, delineate your basic structure, and provide the cornerstone for building an effective group” (University of Michigan, 2015), a point that mirrors the perceived importance of mission and vision statements in organizations (Collins \& Porras, 1996). The University of Michigan draws of the distinctiveness of the constitution as a document intended to address "fundamental principles,” while organizational by-laws detail procedures to uphold order, requiring prospective student organizations to submit both documents.

\section{Methods}

We began by identifying universities that are members of the Association of American Universities (AAU) and have formalized student organizations interested in kinky sexuality. Though representing a limited sample of universities, use of the AAU member universities allowed us to be systematic in data collection through the use of a clearly-defined set of organizations, representing over 1.2 undergraduate students (Association of American Universities, 2015). ${ }^{1}$ To do so, we completed a Google search for each AAU member university by listing the university name AND each of the following search terms: (1) kink, (2) BDSM, (3) dominance and submission, (4) risk-aware consensual kink, (5) safe, sane and consensual and (6) sexual fetishism. For example, University of Chicago AND kink. Then, University of Chicago AND BDSM. And so forth. For each search, we scanned through the first two results pages for relevant references to student organizations. If a reference was found, "records found” was

\footnotetext{
${ }^{1}$ Additional examination showed similar clubs at small, elite liberal arts colleges, including historical men's and women's colleges. However, we were only able to gain access to one student constitution from this group.
} 
entered into database notes. Otherwise, the notes indicated, "no records found.” Roughly 9,000 pages were scanned (Google search results pages include 12 results $\mathrm{x}$ first 2 pages $=24$ results. Six search term combinations were executed for the 62 AAU member universities, equating to 8,928 pages). We also completed an intranet search by visiting each AAU university webpage and executing the same six search term combinations. Finally, internet and intranet searches were completed for a list of existing student clubs and organizations at each university. If student organizations interested in kinky sexuality were listed, the following information was documented: (1) organization name, (2) number of members, (3) formation date (M-YY), (4) website URL, (5) organization's contact information, (6) officer names and contact information and (7) constitution and by-laws.

From our initial search, out of the 62 AAU universities, 18 had recognized student organizations. From this list, we were able to successfully collect 17 student organizations’ constitution that were approved by the relevant universities. While many of these student organizations, much like those related to GLBTQI issues, faced roadblocks gaining official university recognition, our dataset includes successful examples, allowing us to examine the strategies of legitimated organizations with core stigma. It is important to note that not all proposed organizations become sanctioned. A number of applications have been rejected at AAU member universities, where justifications for denial typically include concerns over risk and violence relating to the organization's activities, as well as broader public perception of sanctioning a taboo issue. In data not included here, we also searched for informal student groups on Fetlife.com, confirming our suspicion that not all groups had sought or been able to achieve official sanction. Student organizations focused on kink have emerged at some of the 
most elite universities in the world. Table 1 details each of the student organizations, including the organization's name, university, and year founded.

Insert Table 1 about here-

Our analysis used an open coding and initial axial coding of the constitutions (Creswell, 1994; Neeley, 2013), but with a guiding focus on issues related to stigma, organizational legitimacy, illegitimacy and identification of related discourses. From our review and incorporation of these topics, we identified six emergent themes, stemming from our coding, including (1) Safety, (2) Tolerance, (3) Community Building, (4) Privacy, (5) Definitions of Kink and Links to Other Organizations and (6) Structure of Constitutions. Table 2 provides examples of the content-based themes, and it is important to note that the clubs seemed to have multiple goals, e.g. to meet like-minded people and to advocate for further legitimacy. Insert Table 2 about here-

Table 3 details level one nodes and level two themes for each constitution. Figure 1 provides a graphic overview of these coded nodes versus the number of references in the constitutions, which emphasizes safety as an overriding concern.

Insert Table 3 about here-

Insert Figure 1 about here-

\section{Findings}

To understand how emergent student organizations construct legitimacy around kinky sexuality, we explored the discourses at play in the student organization constitutions. One thing that was apparent upon reading was the boilerplate nature of these documents, with universityprovided student constitution templates detailing specific sections. This contrasted with the way student organizations varied on how detailed or extensive they filled in these sections. For 
example, the first two or three articles typically covered statements of purpose and membership, and generally then moved on to spelling out officers, elections, meetings. Many organizations filled in these first sections in ways that made little mention of the specific people and practices encompassed in the organization. For example, in Iowa State University’s Cuffs constitution, there is mention of "alternative sexuality" and discussion of a safe and supportive environment to discuss “safe, consensual, and non-exploitative forms of alternate human sexuality,” but compared to the constitutions of organizations like Harvard College Munch and Columbia University's Conversio Virium, there is very little about the actual mission and activities of the club in the constitution. The description of the organization's mission and activities is limited to a single paragraph, with far greater emphasis being placed on spelling out of officer roles and duties. However, the degree of elaboration of specific club activities varied. The MIT Student Sex-Positive Club’s constitution described a brief “sex-positive” mission, where "The purpose of the SSC is to provide a safe place for students to discuss sex and sexuality and get information about consent and safer sex practices.” This was also seen with UCSB, which takes the diverse sexuality description, but spent little space defining what that meant in terms of the student organization's specific activities, rendering opaque the specific practices if one did not know what BDSM and fetish activities might entail:

KUFF is a pansexual alternative lifestyle group providing a supportive social environment for education, safety, and exploration of BDSM and fetish activities for UCSB students and the community as a whole (University of California, Santa Barbara, KUFF).

This contrasted, for example, with Harvard College Munch, who included a section not required in the template, a detailed "statement of principles," where they specifically outlined issues of privacy, consent, and community. But in general, our examination of the student club constitutions showed considerable detail about student officers, roles and membership dues, but much less about the specific activities of each organization. 
Nonetheless, from these documents were able to deduce a number of themes. The following sections provide further examination of the themes evident in the constitutions.

\section{Physical Safety}

Not surprisingly, physical safety is a key discourse used by organizations whose core stigma stems from their links with nontraditional sexual practices, as seen with Nevada's brothels (Brents \& Hausbeck, 2005) and men’s bathhouses (Hudson \& Okhuysen, 2009). Physical safety has traditionally been how kink distinguishes itself from actual violence or domination, for example, BDSM widely uses the frame "safe, sane and consensual" as a way to distinguish itself from actual violence or nonconsensual abuse (Weinberg, 1987). Practices such as erotic asphyxiation, referring to the act of intentionally limiting a person's oxygen supply and hematolagnia, also known as blood fetishism, referring to the use of blood in sexual play, unmistakably present safety concerns. Just as men's bathhouses used safe-sex messages to dull stigmatized perceptions (Hudson \& Okhuysen, 2009), student organizations leveraged discourse in their constitutions that emphasized safety, especially relating to educating members about how to perform various practices. Examples included:

We are also committed to including safety as a topic in every educational event we hold, since safety concerns can vary widely from activity to activity and should be taught in conjunction with the activities to which they apply (University of Chicago, Risk-Aware Consensual Kink, emphasis added).

[Article II - Purpose] To educate about and explore the world of kink, promoting acceptance of sexuality and helping peers to navigate the world of kink, safely and consensually (University of California - Berkeley, Kink Club).

Within this study, physical safety included teaching student members how to practice kink safely as part of their sexual and personal development. With genuine risks in BDSM practices, such physical safety concerns motivated discussion in some of the organizations. Some 
constitutions emphasized these physical safety considerations, for example, through mention of variable risks with different activities or demonstrations of safe play:

...BDSM play will not be a part of, nor will be permitted at, any CV meetings or events. Limited demonstrations, however, will be permitted provided that they educate members on safe BDSM practices (Columbia University, Conversio Virium).

\section{Tolerance and a "Safe Space"}

The second theme that emerged, tolerance and safe spaces, fit well with Goffman's (1963) distinction of stigmatized identities, with insiders, those that are socially accepted, and outsiders, those that are socially taboo. The work of student organizations is to support students who practice kink, thus in many ways using the constitution to embrace rather than deny their core stigma. This orientation of creating a "safe space" is similar to how other LGBT groups on high school and college campuses manage homophobia, and fits into universities' concerned with maintaining a tolerant and welcoming campus climate (Kane, 2013). Recognizing this tension in creating and sustaining legitimacy, student organizations interested in kink view themselves as safe spaces, where the taboo of kink that exists in wider society should be absent internally. The organizations are meant to function as safe havens, with the ability to discuss sexuality, as well as issues of wider personal safety, including abuse and assault:

We encourage acceptance and communication between members. We urge them to learn from each other's play styles and experiences and to set aside any assumptions they may have about who people are and what they do. When in doubt, ask. (Columbia University, Conversio Virium)

Furthermore, [the club] creates a space where students may discuss problems in their own relationships, up to and including abuse and assault, which they might not feel comfortable discussion in other spaces (Harvard University, Harvard College Munch).

Tolerance was interrelated with the concept of having a "safe space" for discussion, one that would be free of judgment or harassment:

The Alternative Lifestyle Association and its related meetings and activities are safe spaces for all who practice BDSM; one of the major functions of the organization is to act as a peer support group. People with concerns about the impact of their own BDSM related 
feelings are encouraged to explore them with us. To this end, we wish to engage in dialogue which is supportive, candid, and respectful of others' rights to have differing opinions and limits. However, all those who attend our meetings must refrain from challenging the validity of BDSM in general or others' lifestyles and identities, except when non-consent or safety becomes an issue (Washington University, St. Louis, Alternative Lifestyle Association, emphasis added).

Tolerance also included support services for students dealing with or fearful of sexual assault and violence, echoing the role of these student organizations as spaces that work to protect the emotional safety of members, drawing similarities to the "safe space" discussion with respect to LBGTQI and other sensitive organizations.

We also provide services surrounding intersectionality, privilege and oppression, domestic violence, sexual assault, suicide prevention, self-harm, and sexual health. We are committed to making Brandeis a safe space for students of all genders, sexualities, and identities through confidential peer counseling, educational outreach programs, resources and referrals (Brandeis Queer Resource Center, emphasis added).

Safety was thus both a physical issue and an emotional issue, echoing discourses seen in other sexuality-focused organizations, but with a focus on creating safe spaces for individuals to learn about and explore various gender, sexuality and identity practices without judgment. The notion of a safe space was key to constructing kink as an identity, yet at the same time, this orientation is quite different from LGBT organizations that use other discourses to disrupt heteronormalizing institutions (Dilley, 2013; Griffin, Lee, Waugh \& Beyer, 2004; Maher et al., 2009; Mayberry, 2013).

\section{Community Building}

The third theme involved community building, an important concept in the movement towards gay liberation in the 1960s and 1970s on university campuses (Reichard, 2010). Most of the student organizations interested in kink highlighted community formation of some form, where members could socialize with other people with similar concerns or interests. The goals of community building included formation in the first place, followed by ongoing fellowship and 
bonding. Beyond the student organizations, practitioners of kinky sexuality are often referred to as part of the "kink community" (Newmahr, 2010). This positioned kink as an identity, in line with other LGBTQI identities (Taylor, Whittier \& Morris, 1992), and consequently deserving of individual rights. The use of community building on the student organization level shows an external function, compared to the inward-looking safe spaces. Some groups highlighted events that were open to the wider university, or sometimes even the public. Discussions of communitybuilding events signals to others the value that the student organizations provide to a given campus or region. Community building events also provide pathways for student members to build greater mainstream legitimacy around kink, on a broader scale.

[Purpose] To organize and provide seminars and demonstrations to educated (sic) the community and promote safety and awareness of related topics; To... promote stronger bonds in the community... To organize social events to promote bonding with other members (University of California, Santa Barbara, KUFF).

We will be a social group, offering events, community building, parties, and the option of an arts circle where members share their art and writing relating to BDSM topics (University of Chicago, Risk-Aware Consensual Kink).

Managing the role of student organizations as community builders was defined as a responsibility of the organization's leadership. This is interesting when considering the leadership development principles often associated with serving in a management role of a student organization. For example, leaders of pre-professional organizations often list their role on their resume to communicate managerial experience. Leading community-building activities of a student organization focused on kink provided a similar developmental experience, however, names of student leaders were mostly hidden. This shows a clear distinction in the willingness of students to disclose roles in stigmatized organizations versus traditional pre-professional student organizations.

[Article VII: Officer responsibilities] (University of Chicago, Risk-Aware Consensual Kink). Crunch must have 2-3 coordinators. Coordinator duties include, but are not limited 
to:... Moderating meetings and discussions to ensure that Crunch remains a safe, educational, and community-building space (Cornell University, Cornell Crunch).

\section{Privacy}

The fourth theme involved privacy for student members. Given the organizational purpose, it was unsurprising to find privacy concerns featured strongly in these organizations. This was somewhat paradoxical given the activist goals of some organizations, but can be compared to narratives of "coming out" in the gay community, and the decision of when, how or if one should come out as a matter of individual choice, rather than one that others should decide, which also highlights the continuing stigma associated with these practices.

We respect people's privacy, so we don't out people, not at all, neither explicitly, nor indirectly. We respect people's comfort, and we respect consent, both in theory and in practice (Harvard University, Harvard College Munch)

One's sexuality is considered by many to be a private matter. By attending our meetings and events, one agrees not to divulge to anyone outside the group the names, statements, or actions of anyone else who attends without their explicit permission (Washington University, St. Louis, Alternative Lifestyle Association).

In many organizations, these “outings” were deemed a bannable offense, allowing people to be

barred from events or their membership revoked (University of California, Santa Barbara, KUFF).

Grounds for revocation include making another member feel uncomfortable or threatened, or compromising the privacy of another member (MIT, Student Sex Positive Club).

\section{Defining Kink and Linking to Other Sexuality Groups}

Finally, the studied organizations varied in their core definitions of kinky sexuality, but importantly, many related their mission to other sexuality groups on campus or in wider society. We saw varying attempts to explain and define each organization's understanding of kink. Some organizations saw this as relatively straightforward, with kink as BDSM:

BDSM is herein defined as safe and consensual bondage, domination and submission, and/or sadomasochistic play between responsible adults (Columbia University, Conversio Virium) 
This was also true for the University of Chicago's group, with a focus on BDSM and kink:

We will academically explore various aspects of BDSM by holding lectures, seminars, and panel discussions on topics related to Bondage and Discipline, Dominance and Submission, and Sadism and Masochism hereafter referred to as BDSM, or kink. BDSM is a healthy part of adult sexuality that is relevant to many members of the University community, and this group will provide a safe space on campus where members of the University community can come for information, intellectual debate, and a sense of connection to others with similar interests (University of Chicago, Risk-Aware Consensual Kink).

The group at the University of Chicago also appeared to be undertaking a name change, from "Safe, Sane, and Consensual” to "Risk-Aware Consensual Kink," an interesting point because in explicitly adding kink to the name, this perhaps signaled a further push toward identity-formation with legitimation of the initial safe, sane and consensual framing. The name change also contrasts organizational strategies intended to deflect stigma (Durand \& Vergne, 2015; Vergne, 2012) by instead embracing it’s core stigma through the organization's name.

Other groups defined kink as more diverse, and were not interested in narrow definitions of its meaning:

Kink Harvard College Munch does not seek to define kink for its members. It recognizes that in the popular imagination, "kink" is synonymous with BDSM, but it rejects that notion. While respecting the BDSM interests of many of its members, it seeks to provide a space that is open, accepting, and useful for students with any kinky interest, regardless of what it may be. (Harvard University, Harvard College Munch, emphasis added).

At the same time, the Alternative Lifestyle Association was one of the few organizations to define kink as a distinct sexual identity:

BDSM, like hetero/bi/homosexuality, is a legitimate expression of sexuality, and is not a disorder. The mere fact of being involved in BDSM does not indicate anything bad about someone. We therefore regard complete tolerance of all who practice BDSM as a right and not a privilege. (Washington University, St. Louis, Alternative Lifestyle Association).

Regardless of the definition provided by the organization, for many groups' constitutions, organizational missions and roles were clearly and directly linked to other sexuality groups on campus, as a justification for the new group’s existence: 
Though there are campus groups dedicated to queer sexualities and orientations, as well as groups dedicated to abstinence and other sexual perspectives, no other group exists as a forum for students with kinky sexualities and their interests (Harvard University, Harvard College Munch)

We also found examples of incorporation of kink into existing LBGTQI groups, contrasting organizations, such as the Harvard College Munch, that carved out the unique need for a kink club. Instead, examples such as the Brandeis Queer Resource Center, added kink to larger umbrella organizations promoting a host of stigmatized sexualities on campus:

QRC Staffers receive training in supporting and counseling people of all identities including but not limited to Trans* (the Transgender umbrella), Lesbian, Gay, Bisexual, Asexual, Queer, Intersex, BDSM, Kink, Polyamory, and Allies (Brandeis Queer Resource Center).

\section{Discussion}

We explored how emergent student organizations focused on kink became legitimate and viewed in the same manner as student organizations without taboo associations. Noted activities in these organizations focus heavily on discussion and community formation, pointing to the formation of a kink identity. The primary points of emphasis also include safety and self-exploration, with some organizations including demonstrations, while others host events and promote education through community outreach. Two key insights stem from our analysis.

\section{Taboos, Due Process and Official Recognition}

Our first insight is that university procedures and processes assist emergent organizations to embrace their core stigma in their efforts to gain legitimacy. The process of constructing formalized constitutions that could flow through administratively recognized channels, created an environment where emergent organizations with core stigma could successfully become officially sanctioned. In contrast to successful or “completed” legitimation efforts, in cases of stigma persistence, previous studies have largely emphasized how organizations deflect or hide core stigma (Reinmoeller \& Ansari, 2016; Vergne, 2012) illustrating how organizations 
recognized the persistence of a stigma and worked to subdue its impact. In contrast, our study finds that kink-focused student organizations tended to embrace their stigma as core to their identity, a stigma that required a "safe space," a credible discourse that perhaps required the downplaying of the sexual practices (particularly as optional or recreational), or the mention of sex overall. Becoming officially sanctioned allowed them to build a legitimate organization devoted to gaining outside acceptance, along with educational missions focusing on sexual diversity as a type of consciousness-building activity. Consequently, they represent one template detailing how organizations can both embrace core stigma as requiring certain protections, and simultaneously build legitimacy, at least in cases where there can be official recognition or consciousness-building, as is also seen in the case of gay marriage (Creed et al., 2002). Moreover, once approved, their official status functioned as an overarching protection allowing these organizations to embrace and challenge their core stigma.

Organizational processes are generally standardized and predictable, empowering actors, such as university administrators, to compare organizations' proposals to become sanctioned against those organizations that have previously been sanctioned, a comparison-focused view of legitimacy via due process. Indeed, sanctioning systems shape the perspectives of decision makers to see decisions as operational instead of moral (Tenbrunsel \& Messick, 1999). We have no doubt that official university-level processes for emergent student organizations disseminated by universities created a standardized way to evaluate prospective student organizations, whether they were focused on kink or any other special interest for that matter. Students aspiring to create a new student organization would be encouraged to learn about the process to become sanctioned from the administrative body that governed all such organizations on a given campus. Therefore, 
the administrative body that reviewed applications also served as the gatekeeper for learning about how to craft and submit the applications in the first place.

This is notable because it is commonplace for universities to have hundreds of student organizations and leverage the diversity amongst those organizations to recruit prospective students. Yet, in addition to the bureaucratized university context, the rapidly growing number of student organizations likely enhances the need for standardized review processes. These standard channels happen to de-emphasize the heterogeneity of student interests, instead focusing on the procedural aspect of becoming officially sanctioned. Even in cases of applications that were denied, administrative recommendations included requests for additional advisors and clarity of operational procedures. Denied applications seemed to become sanctioned when resubmitted and alleviated operational concerns. As we see in the form of the constitutions, which carefully follows the templates and boilerplate, this process has also rendered the specific stigmatized interests of students opaque, where instead, the procedural component of the sanctioning decision became the transparent part. While some organizations coordinate elaborate activities, outside of the obligatory one paragraph summary, most constitutions provide little detail on what the organizations actually aim to do, rendering a reader hard-pressed to differentiate a kink club from a jogging club.

This extends prior research in terms of the interaction between transparency and actual practices. As seen in Reinmoller and Ansari’s (2016) study on data infringement and espionage, in contexts where stigmas become opaque and difficult to recognize, organizations are more willing to engage with such stigmatized practices because the public fails to recognize what such practices actually mean. Similarly, on university campuses the philosophies, practices, and artifacts of student organizations became secondary considerations. That is, university decisions 
to sanction were not endorsements of philosophies such as polyamory or dominance and submission, practices such as spanking or bondage, or artifacts including whips and chains, any more than their sanction of student radio would be an endorsement of specific kinds of music. Instead, sanctioning decisions evaluated whether or not the students followed standardized processes so that the decision makers could anticipate a well-managed student organization, as might be seen in other contexts of official recognition, such as the creation of new standards (Lee, 2009; Lee, Hiatt \& Lounsbury, 2014; Sine, David \& Mitsuhashi, 2007). In short, sanctioning decisions emphasized sameness, allowing groups with core stigma to join in the same processes of official recognition as those without stigma.

\section{Credibility and Social Discourses}

Our second insight is that emergent student organizations emphasized discourses that were both pertinent and mainstream throughout society (Gibbs, 1978; Reichard, 2010). Bromley and Meyer (2015) referred to a rights discourse, capturing postwar cultural shifts that expanded civil protections, emphasized individualism and legitimated the rights and values of new organizations. Legitimacy can thus be built for initiatives by positioning those initiatives as localized examples of acceptable social and cultural norms (Creed et al., 2002; Hudson \& Okhuysen, 2009), with additional cyclical goals by the organizations to change minds locally through exposure and rhetoric. By emphasizing community building and safe spaces, kink organizations positioned kink as an identity, and not simply a set of practices, making them deserving of rights in the same way as other LGBTQI organizations. By emphasizing safety, tolerance, and privacy, students successfully aligned the mission and values of their proposed organizations with legitimate issues that universities were already actively engaged in addressing. 
For example, campus safety has been a focal concern of university administrators because the increase in sexual transparency, or coming out, has led to an increase in harassment and discrimination across college campuses (Sausa, 2002; Waldo, 1998). The prescriptive aim throughout the literature has been to improve the acceptance of what Jackson and Terrell (2007) referred to as cultural pluralism on campus, with the intention of building a student body that embraces differences. Yet, while universities have implemented policies and practices to improve acceptance, they continue to struggle with the effectiveness of such top-down initiatives. Whereas with students presenting themselves as curators of safety and community, student organizations focused on kink effectively served as grassroots initiatives that could address similar concerns as administrators, but with minimal resource needs given work by students.

Discourses of rights, safety, tolerance and privacy also align with broader cultural values emphasizing individual rights discourses and self-regulation, which both characterize contemporary neoliberal culture, and have helped legitimate certain sexual rights more broadly (Brents, 2016; Duggan, 2012; Grzanka \& Mann, 2014). Twentieth century sexual liberation was partly due to a shift away from Victorian discourses that framed sexual deviance as a moral problem to discourses of health and safety (Brandt, 1987; Gamson, 1990; Hawkes, 1996). These health and safety frames have been significant elements in the BDSM movement's tentative legitimacy. In addition, however, these concerns have become individualized and mixed into neoliberal messages of tolerance, individual rights and risk. These student constitutions clearly tap into this vein of discourse.

A reliance on boilerplate for proposed student organizations not only highlighted shared concerns with university administrators, but it also allowed for the dismissal, de-emphasis or 
absence of kink in the organizational discourses, with little mention of specific activities (particularly sexual activities) that would be viewed as taboo. Interestingly, the observed pattern that constitutions varied in the degree to which they elaborated upon specific practices and interests perhaps related to the openness of the university or wider community to these topics, as is also seen with formats of marijuana dispensaries in states with legal sales (Hsu et al., 2016). Put another way, by including recognized and new discourses of physical safety, "safe spaces," community building and other topics communicating shared meaning, constitutions were simultaneously able to provide a credible sense of mission and purpose, addressing standard university processes and requirements, while also excluding detailed information on the stigmatized topics. Stigmatized topics and skills became items student members could subsequently discuss and be trained on once the organization became officially sanctioned. This extends work on the emphasis of broader social concerns by way of the organization's discourse, providing additional layers to what Hudson (2008) referred to as normalizing behaviors, which, in the case of our study, limited the refusal of applications based on stigma, via conformity on other factors.

There is value in noting that credibility also stemmed from the students themselves as the authors of the constitutions. Previous studies have explored how individual actors have dual identities, for example, GLBT ministers that represented marginalized sexual identities and also structured roles within the church (Creed et al., 2010). For the ministers, it was their legitimate position within the church that empowered them as agents for building acceptance of marginalized sexual identities as social progress. Similarly, our study of student organizations focused on kink included actors that represented both a marginalized sexual identity and the legitimated role of middle class students within the university system. Consequently, the students 
become change agents, because of their legitimate role in the university, which effectively builds acceptance on their particular campus. Moreover, the aggregate of student organizations with similar interests across AAU university campuses worked towards the higher goal of a more widespread acceptance of kink, thus the reason similar organizations appeared within a few years of one another.

\section{Conclusion and Future Research}

This initial foray into officially-recognized student kink clubs in AAU universities provides us with insights into how emergent student organizations with core stigma become recognized by overarching sanctioning bodies in ways similar to those without taboo associations, an initial step towards further legitimacy. More broadly, their emergence speaks to the shifting agency of organizations with a broader neoliberal discourse, which in part, helped to pave the way for these student organizations, furthering our understanding of the methods by which these types of organizations — who not only have core stigma, but also embrace it as core to their identity—are able to advocate for further legitimacy. We suspect that these small changes could form the small increments that enable later, radical change (Plowman et al., 2007) and going forward, future research should further examine the role of this official recognition in wider legitimacy struggles when it comes to organizations with purpose, particularly as opposed to examples where organizations have not (yet) gained this recognition.

These insights also lead to several provocative questions relating to organizational core stigma, with implications for this work and ideas for future research directions. First, we found that the recognition of taboo organizational purposes is facilitated by impersonal recognition processes with an overarching organization that emphasizes due process. Such recognition highlights documentation and structure over actual practice. Based on our findings, we see how 
the processes and procedures of an umbrella organization transfer enough legitimacy to allow them to embrace their core stigma and challenge that stigma. Further research should examine core stigma in other areas subject to an overarching credentialing or sanctioning body, as might be found in contexts ranging from finance to public health to INGOs.

Second, recognition is positively mediated by emergent organizations’ use of credible, social discourse to emphasize issues that are both pertinent to sanctioning organizations and mainstream throughout society, echoing the role of the organizations within broader social and political advocacy. Here, we attempt to go beyond Suchman’s (1995) enduring work on legitimacy to consider the role of discourses in reframing stigmatized activities and core stigma. We see how overarching processes allow organizations to build outside acceptance and advocate directly against the stigma, but part of this comes from credible social discourses, in this case, related to neoliberal enactment of individual rights and identity pluralism. In terms of future research on organizational core stigma, future research might need to take status into account, given the tendency for emulation of prestigious entities to drive change in society, as we do see prominent universities more strongly represented in our sample. Further, does the construction of kink as a sexual identity and adoption of "kink" into LBGTIQ spaces mean these organizations are not facing a permanent core organizational stigma? This also suggests the need to more clearly differentiate between enduring and occasional stigma in organizations, as well as other boundary conditions. 


\section{References}

Anteby, M., \& Anderson, C. (2014). The shifting landscape of LGBT organizational research. Research in Organizational Behavior, 34, 3-25.

Association of American Universities. (2015). AAU By the Numbers.

Baccaro, L., \& Mele, V. (2011). For Lack of Anything Better? International Organizations and Global Corporate Codes. Public Administration, 89(2), 451-470.

Bamberger, P. A., \& Pratt, M. G. (2010). Editorial: Moving Forward by Looking Back: Reclaiming Unconventional Research Contexts and Samples in Organizational Scholarship. Academy of Management Journal, 53(4), 665-671.

Bauman, Z. (2003). Liquid love: On the frailty of human bonds. Malden, MA: Blackwell Publishers.

Bernstein, E. (2001). The Meaning of the Purchase: Desire, Demand and the Commerce of Sex. Ethnography, 2(3), 389-420.

Brandt, A. M. (1987). No magic bullet: a social history of venereal disease in the United States since 1880: Oxford University Press, USA.

Brents, B. G. (2016). Neoliberalism’s Market Morality and Heteroflexibility: Protectionist and Free Market Discourses in Debates for Legal Prostitution. Sexuality Research and Social Policy, 1-15.

Brents, B. G., \& Hausbeck, K. (2001). State-Sanctioned Sex: Negotiating Formal and Informal Regulatory Practices in Nevada Brothels. Sociological Perspectives, 44(3), 307-332.

Brents, B. G., \& Hausbeck, K. (2005). Violence and Legalized Brothel Prostitution in Nevada: Examining Safety, Risk, and Prostitution Policy. Journal of Interpersonal Violence, 20(3), 270-295.

Bromley, P., \& Meyer, J. W. (2015). Hyper-Organization: Global Organizational Expansion. London, UK: Oxford University Press.

Bromley, P., \& Orchard, C. D. (2015). Managed Morality: The Rise of Professional Codes of Conduct in the U.S. Nonprofit Sector. Nonprofit and Voluntary Sector Quarterly.

Carasco, E. F., \& Singh, J. B. (2003). The Content and Focus of the Codes of Ethics of the World's Largest Transnational Corporations. Business and Society Review, 108(1), 71-94.

Collins, J. C., \& Porras, J. I. (1996). Building your company's vision. Harvard business review, 74(5), 65-77. 
Creed, W. E. D., DeJordy, R., \& Lok, J. (2010). Being the Change: Resolving Institutional Contradiction through Identity Work. Academy of Management Journal, 53(6), 13361364.

Creed, W. E. D., \& Scully, M. A. (2000). Songs of ourselves: Employees' deployment of social identity in workplace encounters. Journal of Management Inquiry, 9(4), 391-412.

Creed, W. E. D., Scully, M. A., \& Austin, J. R. (2002). Clothes Make the Person? The Tailoring of Legitimating Accounts and the Social Construction of Identity. Organization Science, 13(5), 475-496.

Creswell, J. W. (1994). Research design: Qualitative and quantitative approaches. London: Sage.

Dilley, P. (2013). Queer man on campus: A history of non-heterosexual college men, 1945-2000: Routledge.

Duggan, L. (2012). The twilight of equality?: Neoliberalism, cultural politics, and the attack on democracy: Beacon Press.

Durand, R., \& Vergne, J.-P. (2015). Asset divestment as a response to media attacks in stigmatized industries. Strategic Management Journal, 36(8), 1205-1223.

Ebrahim, A., Battilana, J., \& Mair, J. (2014). The governance of social enterprises: Mission drift and accountability challenges in hybrid organizations. Research in Organizational Behavior, 34, 81-100.

Gamson, J. (1990). Rubber wars: Struggles over the condom in the United States. Journal of the History of Sexuality, 1(2), 262-282.

Gibbs, A. (1978). The first amendment and college student organizations. Peabody Journal of Education, 55(2), 131-135.

Giddens, A. (1992). The transformation of intimacy: Sexuality, love and eroticism in modern societies. Stanford, CA: Stanford University Press.

Goffman, E. (1963). Stigma: Notes on the management of spoiled identity. Englewood Cliffs, NJ: Prentice Hall.

Griffin, P., Lee, C., Waugh, J., \& Beyer, C. (2004). Describing roles that gay-straight alliances play in schools: From individual support to school change. Journal of Gay \& Lesbian Issues in Education, 1(3), 7-22.

Grzanka, P. R., \& Mann, E. S. (2014). Queer youth suicide and the psychopolitics of "It Gets Better”. Sexualities, 17(4), 369-393.

Harvard College. (2015). New Student Organization Recognition. from http://osl.fas.harvard.edu/new-student-organization-recognition 
Harvey, D. (2007). A brief history of neoliberalism. Oxford: Oxford University Press.

Hawkes, G. (1996). Sociology of sex and sexuality. Philadelphia: Open University Press.

Heilpern, J. (2015). Not All Non-Discrimination Policies are Created Equal: Analyzing Public Universities' Attempts to Regulate Membership Requirements of Officially Recognized Student Organizations. BYU Education and Law Journal, 2015(2), 523-547.

Horwitz, P. (2014). The Hobby Lobby Moment. Harvard Law Review, 128(1), 154-189.

Hsu, G., Kovács, B., \& Koçak, Ö. (2016). Co-opt or co-exist? A study of medical cannabis dispensaries' identity-based responses to recreational-use legalization in Colorado and Washington, Society for the Advancement of Socio-Economics (SASE) Conference. Berkeley, CA.

Hudson, B. A. (2008). Against all Odds: A Consideration of Core-Stigmatized Organizations. Academy of Management Review, 33(1), 252-266.

Hudson, B. A., \& Okhuysen, G. A. (2009). Not with a Ten-Foot Pole: Core Stigma, Stigma Transfer, and Improbable Persistence of Men's Bathhouses. Organization Science, 20(1), 134-153.

Jackson, J. F. L., \& Terrell, M. C. (2007). Creating and maintaining safe college campuses: A sourcebook for evaluating and enhancing safety programs. Sterling, VA: Stylus.

Jones, R. L., \& Ward, R. (2010). LGBT Issues: looking beyond categories (Vol. 10): Dunedin Academic Press.

Kane, M. D. (2013). Finding "Safe” Campuses: Predicting the Presence of LGBT Student Groups at North Carolina Colleges and Universities. Journal of Homosexuality, 60(6), 828-852.

Kulik, C. T., Bainbridge, H. T., \& Cregan, C. (2008). Known by the company we keep: Stigmaby-association effects in the workplace. Academy of Management Review, 33(1), 216230.

Lakkimsetti, C. (2014). "HIV Is Our Friend": Prostitution, Biopower, and the State in Postcolonial India. Signs, 40(1), 201-226.

Lee, B. H. (2009). The Infrastructure of Collective Action and Policy Content Diffusion in the Organic Food Industry. Academy of Management Journal, 52(6), 1247-1269.

Lee, B. H., Hiatt, S. R., \& Lounsbury, M. (2014). Market Mediators and the Tradeoffs of Legitimacy-Seeking Behaviors in a Nascent Category. Working Paper.

Lindemann, D. J. (2010). Will the Real Dominatrix Please Stand Up: Artistic Purity and Professionalism in the S\&M Dungeon. Sociological Forum, 25(3), 588-606. 
Llewellyn, N. (2004). In Search of Modernization: The Negotiation of Social Identity in Organizational Reform. Organization Studies, 25(6), 947-968.

Maguire, S., \& Hardy, C. (2013). Organizing Processes and the Construction of Risk: A Discursive Approach. Academy of Management Journal, 56(1), 231-255.

Maher, M. J., Landini, K., Emano, D. M., Knight, A. M., Lantz, G. D., Parrie, M., et al. (2009). Hirschfeld to Hooker to Herek to High Schools: A Study of the History and Development of GLBT Empirical Research, Institutional Policies, and the Relationship Between the Two. Journal of Homosexuality, 56(7), 921-958.

Mayberry, M. (2013). Gay-Straight Alliances: Youth Empowerment and Working toward Reducing Stigma of LGBT Youth. Humanity \& Society, 37(1), 35-54.

Meyer, J. W., \& Bromley, P. (2013). The Worldwide Expansion of “Organization”. Sociological Theory, 31(4), 366-389.

Meyer, M. D. E. (2004). "We're too afraid of these imaginary tensions”: Student organizing in lesbian, gay, bisexual and transgender campus communities. Communication Studies, 55(4), 499-514.

Neeley, T. B. (2013). Language Matters: Status Loss and Achieved Status Distinctions in Global Organizations. Organization Science, 24(2), 476-497.

Newmahr, S. (2010). Rethinking Kink: Sadomasochism as Serious Leisure. Qualitative Sociology, 33(3), 313-331.

Newmahr, S. (2011). Chaos, Order, and Collaboration: Toward a Feminist Conceptualization of Edgework. Journal of Contemporary Ethnography, 40(6), 682-712.

Nichols, M. (2006). Psychotherapeutic Issues with “Kinky” Clients. Journal of Homosexuality, 50(2-3), 281-300.

Plowman, D. A., Baker, L. T., Beck, T. E., Kulkarni, M., Solansky, S. T., \& Travis, D. V. (2007). Radical Change Accidentally: The Emergence and Amplification of Small Change. Academy of Management Journal, 50(3), 515-543.

Pontikes, E. G., Negro, G., \& Rao, H. (2010). Stained Red: A Study of Stigma by Association to Blacklisted Artists during the 'Red Scare' in Hollywood, 1945 to 1960. American Sociological Review, 75(3), 456-478.

Prasad, M. (1999). The Morality of Market Exchange: Love, Money, and Contractual Justice. Sociological Perspectives, 42(2), 181-213.

Quinn, S. (2008). The Transformation of Morals in Markets: Death, Benefits, and the Exchange of Life Insurance Policies. American Journal of Sociology, 114(3), 738-780. 
Ragins, B. R. (2008). Disclosure Disconnects: Antecedents and Consequences of Disclosing Invisible Stigmas across Life Domains. Academy of Management Review, 33(1), 194215.

Rehor, J. E. (2015). Sensual, Erotic, and Sexual Behaviors of Women from the "Kink" Community. Archives of Sexual Behavior, 44(4), 825-836.

Reichard, D. A. (2010). "We Can't Hide and They Are Wrong”: The Society for Homosexual Freedom and the Struggle for Recognition at Sacramento State College, 1969-1971. Law and History Review, 28(03), 629-674.

Reinmoeller, P., \& Ansari, S. (2016). The Persistence of a Stigmatized Practice: A Study of Competitive Intelligence. British Journal of Management, 27(1), 116-142.

Richardson, D. (2000). Constructing sexual citizenship: theorizing sexual rights. Critical Social Policy, 20(1), 105-135.

Rojas, F. (2006). Social Movement Tactics, Organizational Change and the Spread of AfricanAmerican Studies. Social Forces, 84(4), 2147-2166.

Rojas, F. (2010). Power Through Institutional Work: Acquiring Academic Authority in the 1968 Third World Strike. Academy of Management Journal, 53(6), 1263-1280.

Sausa, L. A. (2002). Updating College and University Campus Policies. Journal of Lesbian Studies, 6(3-4), 43-55.

Sine, W. D., David, R. J., \& Mitsuhashi, H. (2007). From Plan to Plant: Effects of Certification on Operational Start-up in the Emergent Independent Power Sector. Organization Science, 18(4), 578-594.

Suchman, M. C. (1995). Managing Legitimacy: Strategic and Institutional Approaches. The Academy of Management Review, 20(3), 571-610.

Taylor, V., Whittier, N., \& Morris, A. (1992). Collective identity in social movement communities: Lesbian feminist mobilization. Social perspectives in lesbian and gay studies (New York: Routledge, 1998), 349-365.

Tenbrunsel, A. E., \& Messick, D. M. (1999). Sanctioning Systems, Decision Frames, and Cooperation. Administrative Science Quarterly, 44(4), 684-707.

Tomassilli, J. C., Golub, S. A., Bimbi, D. S., \& Parsons, J. T. (2009). Behind Closed Doors: An Exploration of Kinky Sexual Behaviors in Urban Lesbian and Bisexual Women. The Journal of Sex Research, 46(5), 438-445.

Treviño, L. K., Butterfield, K. D., \& McCabe, D. L. (1998). The Ethical Context in Organizations: Influences on Employee Attitudes and Behaviors. Business Ethics Quarterly, 8(03), 447-476. 
University of Michigan. (2015). Constitution and Bylaws. from https://campusinvolvement.umich.edu/content/constitution-and-bylaws

Vanderbilt University. (2015). New Organizations. from http://www.vanderbilt.edu/studentorgsanchorlink/registering-your-org/new-organizations

Vergne, J.-P. (2012). Stigmatized Categories and Public Disapproval of Organizations: A MixedMethods Study of the Global Arms Industry, 1996-2007. Academy of Management Journal, 55(5), 1027-1052.

Waldo, C. R. (1998). Out on Campus: Sexual Orientation and Academic Climate in a University Context. American Journal of Community Psychology, 26(5), 745-774.

Weeks, J. (2007). The world we have won: The remaking of erotic and intimate life: Routledge.

Weinberg, T. S. (1987). Sadomasochism in the United States: A review of recent sociological literature. The Journal of Sex Research, 23(1), 50-69.

Weiss, M. D. (2006). Mainstreaming Kink. Journal of Homosexuality, 50(2-3), 103-132.

Weiss, M. D. (2011). Techniques of Pleasure: BDSM and the Circuits of Sexuality. Durham, NC: Duke University Press.

Wolfe, A. W., \& Blithe, S. J. (2015). Managing Image in a Core-Stigmatized Organization: Concealment and Revelation in Nevada's Legal Brothels. Management Communication Quarterly, 29(4), 539-563.

Yoshino, K. (2006). Covering: The Hidden Assault on Our Civil Rights. New York: Random House.

Zelizer, V. A. (1978). Human Values and the Market: The Case of Life Insurance and Death in 19th Century America. American Journal of Sociology, 84(3), 591-610.

Zelizer, V. A. (1983). Morals and Markets: The Development of Life Insurance in the United States. New Brunswick: Transaction Books. 
Figure 1. Nodes Coded by Number of Coding References

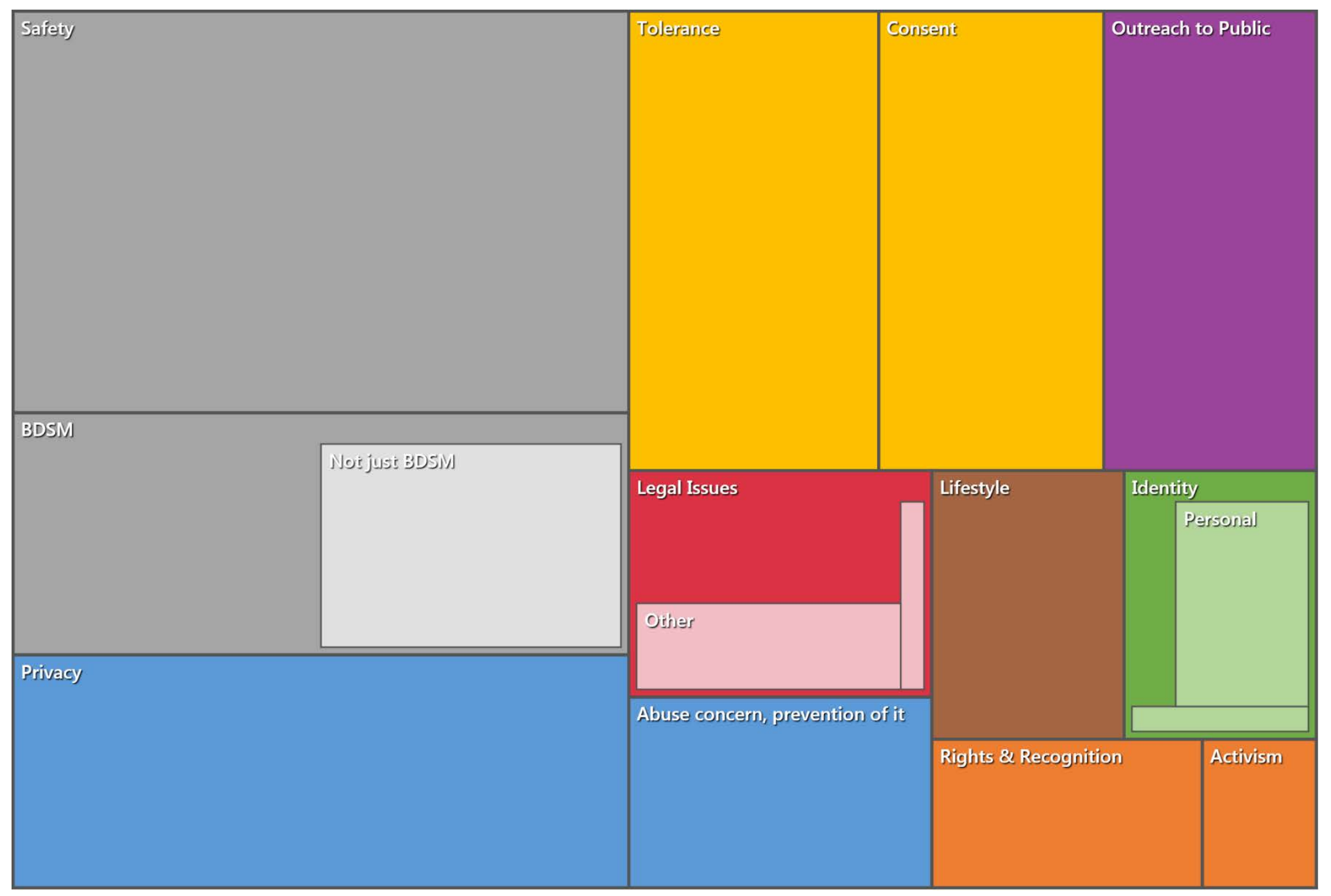


Table 1. Historical Emergence of Sanctioned Kink Student Organizations

\begin{tabular}{c|l|l}
\hline Year Founded & University & Organization Name \\
\hline 1998 & University of Wisconsin & Sex Out Loud \\
\hline 2000 & Iowa State University & CUFFS \\
\hline 2004 & Washington University St. Louis & The Alternative Lifestyle Association (ALA) \\
\hline \multirow{2}{*}{2006} & Massachusetts Institute of Technology & MIT Student Sex-Positive Club \\
\hline \multirow{2}{*}{2011} & Columbia University & Conversio Virium \\
\cline { 2 - 3 } & University of Chicago & $\begin{array}{l}\text { Safe, Sane, and Consensual (later renamed to Risk-Aware } \\
\text { Consensual Kink) }\end{array}$ \\
\hline \multirow{2}{*}{2012} & University of California-Santa Barbara & Kink University: A Fetish Fellowship (KUFF) \\
\hline \multirow{2}{*}{2013} & Brandeis University & Brandeis Queer Resource Center \\
\cline { 2 - 3 } & Harvard University & Harvard College Munch \\
\cline { 2 - 3 } & Stony Brook University & SBU The Next Generation \\
\cline { 2 - 3 } & Penn State University & Kink Positive \\
\cline { 2 - 3 } & University of Minnesota & Queer Student Cultural Center \\
\cline { 2 - 3 } & Cornell University & Cornell Crunch \\
\cline { 2 - 3 } & Stanford University & Kardinal Kink \\
\cline { 2 - 3 } & Case Western University & Case Undergraduate Fetish Foundation (CUFF) \\
\cline { 2 - 3 } & Northwestern University & Therthwestern University Kink Education Society (NUKES) \\
\cline { 2 - 3 } & University of California-Berkeley & Trojan Munch Club \\
\cline { 2 - 3 } & University of Southern California & \\
\cline { 2 - 3 } & &
\end{tabular}


Table 2. Coding Themes and Data Exemplars

\begin{tabular}{|c|c|}
\hline $\begin{array}{l}\text { Coding } \\
\text { Themes }\end{array}$ & Exemplars from the Data (emphasis added) \\
\hline \multirow[t]{2}{*}{ Safety } & $\begin{array}{l}\text { 1. The purposes of KUFF are...to provide a safe and open environment to } \\
\text { discuss alternative lifestyles and practices... To organize and provide } \\
\text { seminars and demonstrations to educated [sic] the community and promote } \\
\text { safety and awareness of related topics (University of California, Santa } \\
\text { Barbara, KUFF). }\end{array}$ \\
\hline & $\begin{array}{l}\text { 2. The purpose of Kink Positive is to help educate the PSU community on } \\
\text { alternative sexuality issues, to create a safe environment for people to meet } \\
\text { and share ideas about alternate sexuality (i.e. the kink, poly, and swing } \\
\text { communities), and to provide information on health and safety to our } \\
\text { members and the PSU community (Penn State University, Kink Positive). }\end{array}$ \\
\hline Tolerance & $\begin{array}{l}\text { 1. People with concerns about the impact of their own BDSM related } \\
\text { feelings are encouraged to explore them with us. To this end, we wish to } \\
\text { engage in dialogue which is supportive, candid, and respectful to others' } \\
\text { rights to have differing opinions and limits. However, all those who attend } \\
\text { our meetings must refrain from challenging the validity of BDSM in general } \\
\text { or others' lifestyles and identities, except when non-consent or safety } \\
\text { becomes an issue (Washington University St. Louis, Alternative Lifestyle } \\
\text { Association). }\end{array}$ \\
\hline \multirow[t]{2}{*}{$\begin{array}{l}\text { Community } \\
\text { Building }\end{array}$} & $\begin{array}{l}\text { 1. To provide support, community, and safe space for individuals who are } \\
\text { interested/involved/supportive of non-normative sexuality and to provide } \\
\text { information about the related communities (Case Western University, } \\
\text { CUFF). }\end{array}$ \\
\hline & $\begin{array}{l}\text { 2. The purpose of the Organization shall be: ... B. To create a visible } \\
\text { campus community of open-minded students at Stony Brook University } \\
\text { who want to learn more and get feedback on topics concerning kink; C. To } \\
\text { provide a venue for students at Stony Brook University to discuss and share } \\
\text { their experiences in the BDSM (or other kink) community that is free of } \\
\text { social pressure and judgment based on sexual orientation/interest... (Stony } \\
\text { Brook University, SBU TNG). }\end{array}$ \\
\hline \multirow[t]{2}{*}{ Privacy } & $\begin{array}{l}\text { 1. BDSM is considered by many to be a private matter. In addition, } \\
\text { misconceptions about BDSM remain widespread and may be damaging. By } \\
\text { attending our meetings and events, one agrees not to divulge to anyone } \\
\text { outside the group the names, statements, or actions of anyone else who } \\
\text { attends without their explicit permission (Columbia University, Conversio } \\
\text { Virium). }\end{array}$ \\
\hline & $\begin{array}{l}\text { 2. No list of members will be published or available to anyone other than the } \\
\text { current officers of the SSC (MIT, Student Sex-Positive Club). }\end{array}$ \\
\hline $\begin{array}{l}\text { Definitions of } \\
\text { kink }\end{array}$ & $\begin{array}{l}\text { 1. The word "kink" here is used as an umbrella term which includes, but it } \\
\text { not limited to: BDSM (bondage, discipline, Domination/submission, } \\
\text { sadism/masochism), fetishes, and many other practices between consenting } \\
\text { humans that are considered paraphilic by the medical and social } \\
\text { establishment (Cornell University, Crunch). }\end{array}$ \\
\hline
\end{tabular}




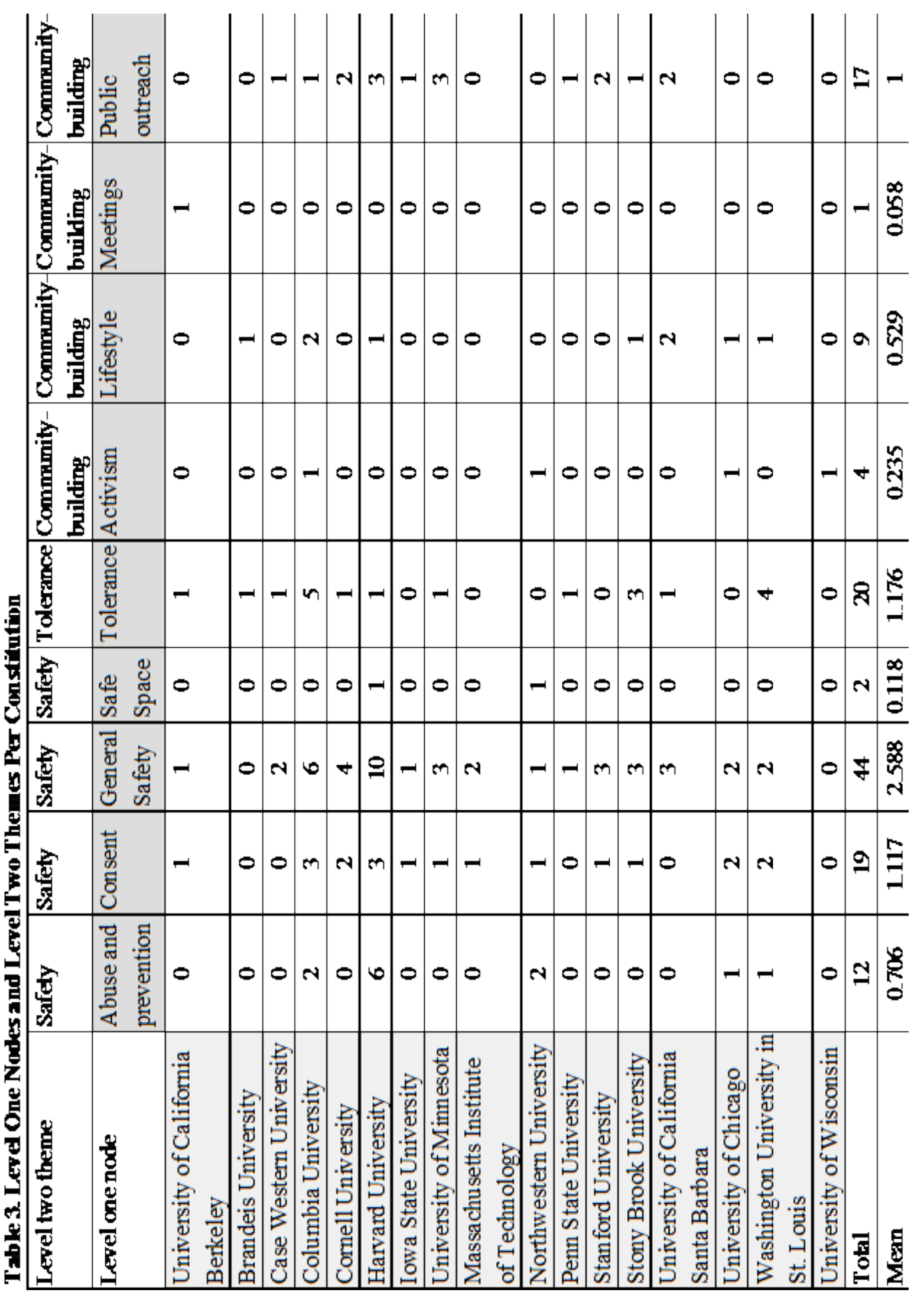




\begin{tabular}{|c|c|c|c|c|c|c|c|c|c|c|c|c|c|c|c|c|c|}
\hline 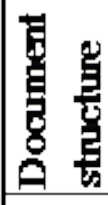 & 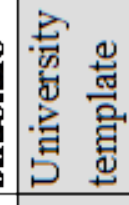 & - & 0 & & 0 & 10 & 0 & 0 e & & 10 & 0 & 0 & 0 & 0 & 0 & & $-1 \begin{array}{l}\infty \\
\ddot{E} \\
0\end{array}$ \\
\hline 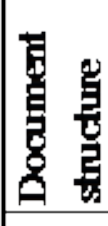 & 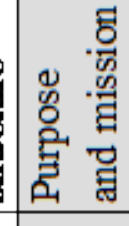 & 0 & 0 & & 0 & - & 0 & 0 e & & $m c$ & - & 0 & 0 & 0 & 0 & -0 & 0 \\
\hline 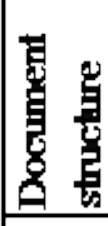 & & 0 & 0 & & 0 & 10 & 0 & 00 & $b$ & -0 & 0 & 0 & 0 & 0 & 0 & $0-$ & $-\underbrace{\infty}_{0}$ \\
\hline 量 & & 0 & 0 & $=$ & 10 & 10 & 0 & 00 & $b$ & 0 & 0 & 0 & 10 & 0 & 0 & O N & $N \stackrel{\infty}{=}$ \\
\hline 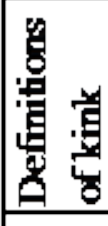 & 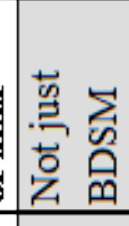 & 0 & 0 & $=0$ & - & -1 & -1 & -0 & & -0 & 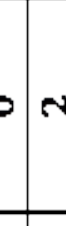 & $N$ & - & 0 & - & $0 \pm$ & $\pm \infty$ \\
\hline 噌 & & - & 0 & & - & $1-$ & 0 & & $\theta$ & 10 & 0 & - & - & $N$ & N & & 0 \\
\hline 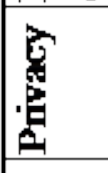 & 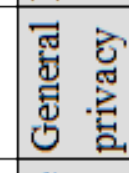 & 0 & 0 & $0:$ & - & $\infty$ & 0 & $\mathrm{NO}$ & $n$ & -0 & - & 0 & $\mathrm{~N}$ & $m$ & N & $0 \%$ & $8 \%$ \\
\hline 总 & 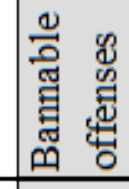 & 0 & 0 & 0 & 0 & $m$ & 0 & 0 & $\partial$ & -0 & 0 & 0 & 0 & 0 & 0 & 0. & + \\
\hline 貢 & 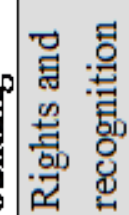 & o & 0 & & 0 & 10 & | & & 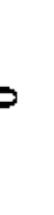 & 10 & & - & 0 & 0 & - & on & $-\frac{0}{0}$ \\
\hline
\end{tabular}

